Although it is possible to quibble about exact figures, the abiding message of the Kinsey Reports, ironically supported by the work of the predecessors whom Kinsey scorned as working from much too small and skewed samples, stands: sexual behaviour in the human, male and female, is far more diverse than the model set up by conventional morality would have us believe. For many they carried the reassuring message "You're not alone".

Lesley A. Hall is at the Wellcome Institute for the History of Medicine, 183 Euston Road, London NW1 IBN, UK.

\section{Dogma or debate?}

\section{Old Wine, New Flasks: Reflections on Science and Jewish Tradition}

By Roald Hoffman and Shira Leibowitz Schmidt

W. H. Freeman: 1997. Pp 362. \$28.95, £17.95

\section{George Klein}

The authors - one a Nobel laureate in chemistry, the other a Talmudic scholar and teacher who is the mother of six children - offer the reader "juxtaposed tales of science and Jewish religious tradition, in which scientists, doing experiment and theory, face concerns similar to those of human beings in the Bible, the sages of Talmud, and thoughtful people throughout the ages". There is, they say, "a parallel not only in subject matter, but in the logic applied. There is a set of hypotheses, precedent, a way of thinking .... There is incredible continuity and clever, clever thought."

This is a well written book. It is witty and erudite, full of the most unexpected associations and contrasts. It alternates between the sublime and the mundane, between deep thought and funny anecdotes while jumping, entertainingly, between different styles, including fictive e-mail exchanges and short theatrical plays. Both authors must be great teachers. Nevertheless, the basic idea of the book, as expressed in the title metaphor, is an absurdity, or, to use a Hungarian proverb, "an iron ring made out of wood".

Even though the Talmudist author is apparently well versed in modern science, her reasoning rests, naturally, on the firm basis of her religious convictions. This includes a more or less outspoken belief in the divine origin of some of the ancient texts. It could hardly be otherwise, as the biblical stories about the creation of the world, the words and miracles of God, and His direct intervention in the lives and doings of His people provide the basis for all Talmudic reasoning. The rest is interpretation and commentary or practical rules.

It cannot be denied that the dynamic intensity of the continuous debates in the yeshivot (Jewish Orthodox religious colleges) are reminiscent, at least superficially, of the discussions at some of the best scientific

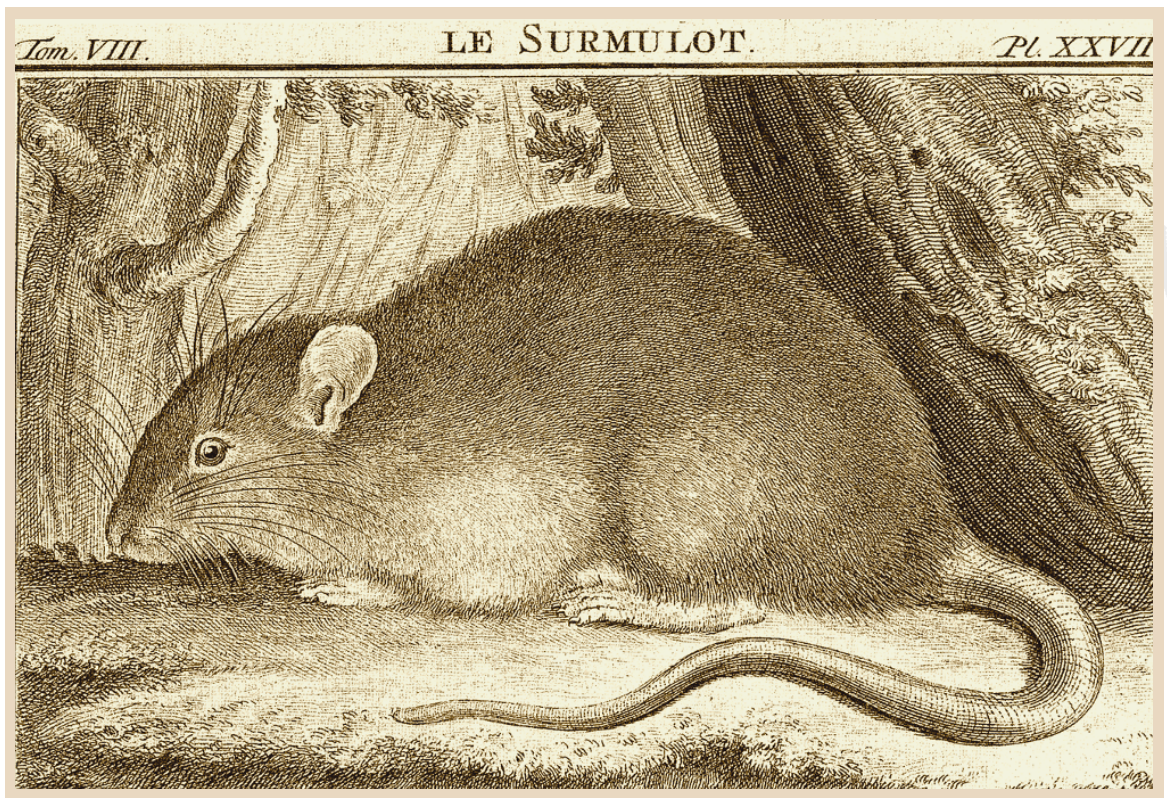

Rat pack

Eighteenth-century engraving from a drawing by Buffon of "Le Surmulot", the brown rat. The picture is reproduced in The Rat: A Perverse Miscellany by Barbara Hodgson (Ten Speed Press, \$15.95), an elegant and entertaining little

meetings. Living in the neighbourhood of some religious schools during my working periods in Jerusalem, I could not fail to notice the agitated joy of the traditionally dressed young men, often engaged in lively exchanges, as they walked to school every morning. Except for their garments, they reminded me of some unforgettable post-breakfast walks at Cold Spring Harbor or at a Gordon Conference. But don't be misled. In spite of superficial similarities at the psychological and sociological level, the core substance is totally different.

Not that the habit of argumentation and scholarly competition in the Talmudic tradition may not have contributed to the evolution of scientific discussions. When another Nobel laureate, the great American physicist Isidor Rabi, was asked whether his attendance at a religious school in pre-war Poland had influenced his later scientific development, he answered in the affirmative. But he also pointed out that the most important influence came from his mother. When ten-year-old Isidor came home for lunch, she did not ask whether he did well at school, like most other mothers. She wanted to know whether the boy had asked a good question.

So far so good. But the crux of the matter is that the discussions at the yeshivotnever question the basic assumptions about God (spelled G-d) and "His" absolute truths.

How do scientists who are also Orthodox Jews handle the contradictions between religion and science within themselves? The legendary and recently deceased Professor Yeshayahu Leibowitz, who happened to be the paperback devoted to the animal's habits and accomplishments, but most of all to centuries of literary and pictorial evocations (from Hieronymus Bosch to James Bond) that show our deep fascination with this despised rodent.

father-in-law of the second author, is a particfessor of chemistry, but also lectured and wrote on many other subjects, such as neurophysiology, philosophy, literature and numerous Judaistic themes. A meticulously observant Orthodox Jew, Leibowitz had a strictly compartmentalized mind. The religious law had to be kept and not discussed, because it was the law. Philosophy was the realm of sceptical criticism, science was the field of experimentation and discussion. Molecular biology was the greatest scientific advance of the century but it could not explain embryonic development or the workings of the mind, now or in the future. Leibowitz was a Kantian dualist with a watertight partition between non-communicating worlds, each of which had its consistent logic.

The authors of this book do not attempt to pierce this partition, nor do they acknowledge its impenetrability. Rather, they try to joke it away. I can only admire the way in which they use a gamut of scientific explanations for biblical episodes such as Moses' turning bitter waters into sweet by throwing a particular tree into a lake, following direct divine instruction. Having presented a variety of chemical guesses in e-mail form, the authors and some of their real or fictitious discussion partners are finally put in their place by an outstanding biblical scholar, Professor Moshe Greenberg. He is quoted as saying: "Such attempts of scientists to rationalize or naturify Biblical miracles, while undertaken in a spirit of piety, defeat the very purpose of the Bible in reporting them. What place a faith ularly interesting case in point. He was a pro- 
in miracles has in the belief of moderns is a separate serious issue that no eviscerating rationalisation of Biblical miracle stories can help to determine."

Miracles apart, the book contains valid insights about natural phenomena in the ancient texts. The Talmud, like other sources of old wisdom that have been collected and preserved over many centuries, records innumerable pertinent observations about the world outside and within us. Some of them belong to the realm of chemistry, and their thorough presentation from both sides provides instructive entertainment. Basically, however, they are not very different from other ancient sources of popular wisdom, 'traditional medicine' or even folklore.

Readers with a warm feeling towards the Zionist ideal may welcome the section on tekhelet, a blue dye derived from a snail, that has been used in accordance with direct biblical instruction to colour religious garments and instruments of prayer over many centuries and has reemerged in the Israeli flag. But the theatrical conversation between Theodor Herzl and another Zionist leader, David Wolffsohn, at the time of the 1897 Zionist Congress in Basel, quoted as havingled to this choice, sounds contrived.

The further projection of the story to the outrageous murder of Yitzhak Rabin, whose coffin was wrapped in the same colours, departs from the main topic of the book in a disturbing way. Its reading induced profound melancholy in the reviewer that was amplified by the ensuing little play. It presents the arguments that have apparently provided the ideological basis for the murder, without an explicit condemnation or comment by the authors. According to these arguments, Rabin was to be regarded as a rodef, a pursuer of the Jewish people, a definition that justifies murder according to an ancient law. The fact that the murder was committed at a time when the prime minister had decided, after much agonizing reappraisal, to take the road to peace, is a tragedy that cannot be glossed over by just reporting the differing opinions among the Orthodox themselves on this matter, as the authors do. It is a clear illustration, if any were needed, how strict adherence to a certain interpretation of a religious law may carry the seeds of the ultimate intolerance within itself.

I am reminded, mutatis mutandis, of the expulsion of Spinoza - whom Bertrand Russell called "the noblest and most lovable of the great philosophers" - from the Jewish community of Amsterdam in 1656 and the accompanying curse that called on "God's fury and his full malediction" to descend on him. No amount of erudite chemistry, amusing and profound examples of ancient wisdom, no instructive and often funny connections between the old laws or traditions and modern science, can tone down the dangers of religious fundamentalism. Are the authors shying away from the clear condemnation of the
Rabin murder that can be reasonably expected from every moral person, in order to avoid hurting the feelings of religious Jews who share the ultra-orthodox opinion? Do they refrain from addressing some of the incompatibilities between religious judgement and modern science for a similar reason? Perhaps so. But the tactful avoidance of these crucial issues leads to absurdities.

To mention one example, the authors claim there is a "substantive similarity" between the methodology of the Jewish oral law (such as the Talmud) and science, in that they "share a commitment to close analysis and a tradition of citation". The difference is, they say, that Jewish religious discourse always quotes old and even very old statements, whereas science cultivates the new. They add that this "could be the pace of advance; we think it is in part a culture of evaluation of the new. The oedipal urge is stronger in science."

This overlooks — or avoids - the point that everything can be questioned in science but not in religion. There is no scientific paradigm that cannot collapse like a house of cards as soon as new evidence disproves it. Religion adheres to its old texts because of their presumed divine origin. To attribute this difference to the relative strength of an oedipal urge is either another joke or, in the worst case, yet another illustration of the strange blind spots that may affect even the most erudite among us, when we wish to defend our preconceived notions.

The influence of dominating figures is another case in point. The authors emphasize that religious scholars, like scientists, have the right and responsibility to dissent from the views of an authority and that they have a similarly high respect for debate and dialectics. This does not include the right to question the fundamental assumptions, however - as the reviewer, but not the book, hastens to add. Here is the fundamental difference between religion and science. As Niels Bohr pointed out in Atomic Physics and Human Knowledge (Wiley, 1958), the goal of science is not to formulate the "universal truth". It has a "more modest but relentless goal: the gradual removal of prejudices". This relentless difference cannot be glossed over by entertaining and instructive similarities between scientific and Talmudic reasoning.

In the final epilogue, the authors list a number of topics that they have avoided, which can be summed up by stating that they have mainly avoided confrontation. What a pity. Taking a less cautious course, they might have succeeded in putting some old wine into new flasks after all, although they would have produced a more controversial brew. As it stands, they have generated only a finely dispersed emulsion of oil in water. Many readers may like it nevertheless.

George Klein is at the Microbiology

and Tumour Biology Center, Karolinska Institute,

S-17177 Stockholm, Sweden.
New in paperback

Plants, People, and Culture: The Science of Ethnobotany

by Michael J. Balick and Paul Alan Cox

W. H. Freeman/Scientific American Library, $\$ 19.95$, 115.95

"An exciting book, clearly written and well illustrated. It impresses on readers the value of plants in their lives and cultures and the critical need to conserve plant biodiversity for future generations", David Pimental, Nature 382, 412 (1996)

The Stork and the Plow: The Equity Answer to the Human Dilemma by Paul R. Ehrlich, Anne H. Ehrlich and Gretchen C. Daily

Yale University Press, $\$ 16, £ 11$

"A well-reasoned account of how poverty forces unsustainable use of natural resources [and] a careful and balanced treatment of developments in agriculture... that may help food production to stay ahead of population growth", Basia Zaba, Nature 379, 308 (1996)

Five Golden Rules: Great Theories of 20th-Century Mathematics - and Why They Matter

by John L. Casti

Wiley, $\$ 16.95$

"Hard going from the beginning, although well worth the investment for anyone who really wants to learn about some of the contemporary mathematics that affects our everyday lives.... The five themes chosen by Casti are game theory, topological fixedpoint theory, singularity theory, computation theory and optimization theory. He makes no attempt to entice you in. He assumes you want to know. For those who do, the reward is substantial", Keith Devlin, Nature 379, 128 (1996)

The Mathematical Universe: An Alphabetical Journey Through the Great Proofs, Problems, and

\section{Personalities}

by William Dunham

Wiley, $\$ 16.95$

"Artfully, Dunham conducts a tour of the mathematical universe... he believes these ideas to be accessible to the audience he wants to reach, and he writes so that they are", Jerry P. King, Nature 373,

206 (1995)

\section{The Origins of Virtue}

by Matt Ridley

Penguin, $£ 8.99$

"Extremely well written... Ridley does an admirable job of documenting the mutual dependencies implied by Darwin", Frans de Waal in Nature 383, 785 (1996) 